\section{HEREDITARY HAEMORRHAGIC TELANGIECTASIA}

\author{
BY
}

C. P. PETCH, M.D., M.R.C.P.

Physician, St. Helier Hospital, Carshalton, Surrey

Hereditary haemorrhagic telangiectasia, sometimes known as the Osler-Rendu disease (Rendu, 1896 ; Osler, 1901), is a well-recognized but somewhat rare condition whose essential features are defined by its name. The characteristic lesions are telangiectases, or aggregations of dilated small vessels, initially minute but gradually increasing in size, scattered over the skin of the face and arms and the mucosa of the nose, mouth, and pharynx. They are also recorded as occurring at less usual sites such as the bronchial tree and the bowel. These defects are not present at birth but develop later, often in middle life. Their constituent vessels are formed by a single layer of endothelium and tend to bleed, most commonly in the form of recurrent epistaxis, to such an extent as to produce a severe microcytic anaemia or even death. Usually haemorrhage or anaemia brings the patient to the doctor. The familial incidence is very pronounced and is considered to show inheritance of the trait as a Mendelian dominant. The following pedigree is an addition to the available data.

\section{Case History}

The patient (II 3), a woman aged 59, came to hospital feeling " run down." She was very pale and gave a history of repeated severe bleeding from the nose. Examination of the blood showed : haemoglobin, $30 \%$ (Haldane); red blood cells, $3,570,000$ per c.mm.; colour index, 0.4. No other abnormality was at first obvious, but, when her colour had been a little restored by the administration of iron, telangiectases were clearly visible on the face and arms, in the conjunctiva of the right eye, and in the mucous membrane of the mouth and nose. She stated that she had only recently noticed these spots, but questioning revealed that three of her sisters (II $5,6,7$ ) had similar facial blemishes. Two of these had died in old age, and

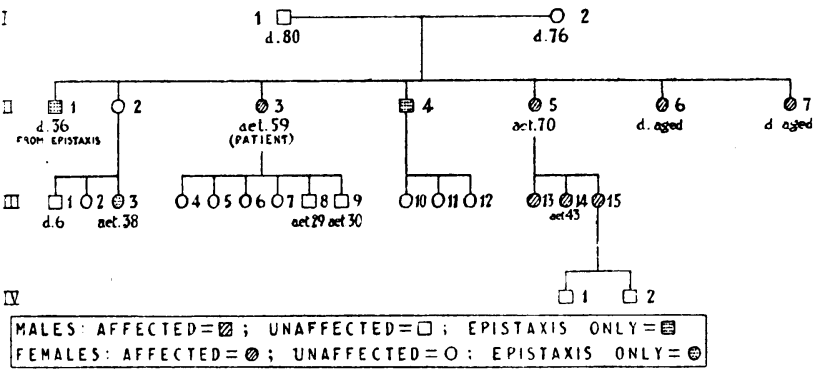

the third, aged 70 , could not come for inspection. Her two brothers (II 1, 4) had severe epistaxis, one of them dying from this cause at the age of 36 , which marks him (II 1) as a probable sufferer. The remaining sibling is unaffected. The patient's own six children do not yet show the condition, but since the eldest is only 30 they have time to develop it. Among her nephews and nieces a family of three sisters are all affected (III 13, 14, 15). One (III 13) has emigrated to Canada, where she is shown at clinical meetings as a case of a rare disease with "spots" on the face, presumably of the family complaint. Another (III 14) came to see me by invitation and showed typical telangiectases on the face and arms, but has not yet suffered from bleeding. The third (III 15) has not been able to attend, but is said to have identical lesions. The descendants of the patient's unaffected sibling are also of interest. One (III 3) has severe epistaxis at the age of 38 ; another (III 1) died suddenly at the age of 6 , bringing to mind the recorded instances of intracranial haemorrhage in early life in these families which have led some writers (Goldstein, 1921; Mekie, 1927) to poskulate cerebral telangiectases.

\section{Discussion}

Interest has been aroused in the haematology of this condition by Penfold and Lipscomb's (1943) report of a family in which hereditary haemorrhagic telangiectasia was associated with elliptocytosis of the red cells. Elliptocytosis is a feature of primitive marine vertebrates, and these authors put forward the interesting hypothesis that both abnormalities represent a harking back to an amphibian ancestor in which skin and oro-nasal mucosa have a respiratory function and are therefore highly vascular. I am indebted to Dr. R. H. Trinick, of the South London Blood Supply Depot, for examining my patient's red cells for elliptocytosis, which he reports to be absent.

Another recent report (Singer and Wolfson, 1944) describes a family affected by hereditary haemorrhagic telangiectasia in which all three cases examined were unusual in having strongly positive tourniquet tests. This led the authors to regard the disease as one of a group of "capillary heredopathies," the other members being hereditary familial vascular purpura and pseudohaemophilia. In the present case the tourniquet test, as it is usually described, was negative.

A recent introduction in the therapeutic field-rutin-has been claimed as valuable in preventing bleeding from the telangiectases by virtue of its beneficial effect on capillary fragility. This substance is a flavone glucoside allied to hesperidin and derived from Fagopyrum sagittatum. It was tried in the present instance in doses of up to $40 \mathrm{mg}$. three times a day for periods of a month at a time, but over a year there was no difference between the periods when rutin was taken and when it was not. Attempts at cautery of the nose have met with the usual rather disappointing results. Plugging has not yet been necessary; the use of oxidized cellulose gauze has been recommended in this connexion (Kennedy, 1947). 'In my patient an adequate blood count is being maintained (latest haemoglobin, $90 \%$ ) by the administration of iron-one "fersolate" tablet thrice daily. She therefore represents the middle range of an abnormality the severity of which varies from complete harmlessness to a cause of early death.

\section{REFERENCES}

Goldstein, H. I. (1921). Arch. intern., Med., 27, 102

Kennedy, H. P. (1947). New Engl. J. Med., 237, 180.

Mekie, E. C. (1927). British Medical Journal, 1, 423.

Osler, W. (1901). Johns Hopk. Hosp. Bull., 12, 333.

Penfold, J. B., and Lipscomb, J. M. (1943). Quart. J. Med., 12, 157. Rendu (1896). Bull. Mém. Soc. méd. Hôp. Paris, 13, 731.

Singer, K., and Wolfson, W. Q. (1944). New Engl. J. Med., 230

The Ministry of Health, after consultation with the National Pharmaceutical Union and the Association of Executive Councils, has prepared a model scheme for testing the quality and amount of drugs and appliances supplied by chemists. It is proposed that England and Wales will be divided into six divisions, in each of which an analyst will work under contract with the executive councils in the division. Appliances will be tested by the Testing House of the Manchester Chamber of Commerce. When a test is to be carried out the clerk of the executive council will arrange for an official prescription to be written in duplicate and signed by a medical practitioner on the council's list; the practitioner will not be told the name of the chemist to whom the prescription is to be presented for dispensing. An agent of the executive council will present the prescription, and when it is dispensed he will tell the chemist that it is required for testing. The certificate of analysis given by the analyst or by the Testing House will be considered by the chairman or deputy chairman of the Pharmaceutical Service Committee and a registered pharmacist member of the committee. If they agree that no further action is required, the chemist will be informed that he may forward the prescription to the pricing bureau for pricing. If they consider that further action is warranted, the matter will stand referred to the Pharmaceutical Service Committee, which will investigate it as if a complaint had been made against the chemist in respect of an alleged failure to comply with his terms of service under Para. 2 of Regulation 4 of the National Health Service (Service Committees and Tribunal) Regulations, 1948. 